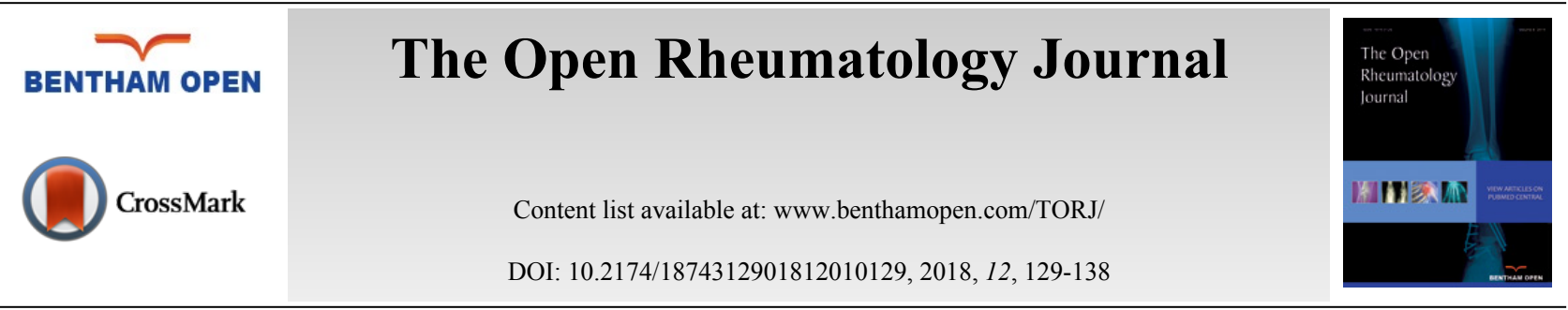

RESEARCH ARTICLE

\title{
Assessment of Mean Platelet Volume in Patients with Systemic Lupus Erythematosus
}

Lisandra Torres Hartmann ${ }^{1, *}$, Ana Paula Alegretti ${ }^{1}$, Alice Beatriz Mombach Pinheiro Machado ${ }^{1}$ Eduardo Ferreira Martins², Rafael Mendonça da Silva Chakr ${ }^{2}$, Andrese Aline Gasparin ${ }^{2}$ and Odirlei André Monticielo ${ }^{2}$

${ }^{I}$ Department of Clinical Pathology, Hospital de Clínicas de Porto Alegre, Porto Alegre, Brasil

${ }^{2}$ Division of Rheumatology, Department of Internal Medicine, Hospital de Clínicas de Porto Alegre, Universidade Federal do Rio Grande do Sul, Porto Alegre, Brasil

Received: May 30, 2018

Revised: July 28, 2018

Accepted: August 5, 2018

\section{Abstract:}

\section{Introduction:}

The Mean Platelet Volume (MPV) is a platelet activation biomarker that has been recently correlated with disease activity in SLE. We aimed to evaluate the MPV in patients with SLE comparing it with healthy individuals, to study the correlation between MPV and SLE Disease Activity Index (SLEDAI) in SLE patients and to analyze possible correlation between MPV and Erythrocyte Sedimentation Rate (ESR), C-Reactive Protein (CRP), and complement components C3 and C4.

\section{Methods:}

This is a cross-sectional study in which 81 patients with SLE according to the American College of Rheumatology (ACR) diagnostic classification criteria and 58 healthy controls were included. Active disease was defined as SLEDAI $>0$.

\section{Results:}

Patients with active SLE had decreased MPV when compared to inactive disease group (10.0 $\pm 0.7 \mathrm{fL} v s .10 .7 \pm 1.0 \mathrm{fL}, p=0.005$, respectively) and when compared to control group $(10.9 \pm 1.0 \mathrm{fL}, p<0.001)$. Our study found a weak negative correlation between the SLEDAI and the MPV $(\mathrm{r}=-0.29, p=0.009)$. There was no correlation between MPV and CRP, ESR, C3 and C4. Also, no correlation between SLEDAI and CRP, ESR, C3 and C4 was found.

\section{Conclusion:}

MPV decreases in patients with active SLE and is inversely correlated with SLEDAI.

Keywords: Mean platelet volume, Systemic lupus erythematosus, Systemic lupus erythematosus disease activity index, Autoimmunity, Biomarker, ESR.

\section{INTRODUCTION}

Systemic Lupus Erythematosus (SLE) is a chronic autoimmune inflammatory disease, with a pleomorphic nature regarding the pathogenesis and onset of clinical manifestations. The development of autoimmunity in SLE is related to the loss of immunological tolerance and immunoregulatory control [1].

\footnotetext{
* Address for correspondence to this auther at the Serviço de Patologia Clínica do Hospital de Clínicas de Porto Alegre - HCPA, Rua Ramiro Barcelos, 2350 - Largo Eduardo Zaccaro Faraco, $2^{\circ}$ Andar Laboratório de Patologia Clínica, Porto Alegre, Rio Grande do Sul, Brasil, Zip Code: 90035-903, Tel: +555133598316; E-mail: 1hartmann@hcpa.edu.br
} 
SLE is a disease which evolves with periods of activity and remission. It is essential for the clinician, during the patient's follow-up, to verify in which phase the same is found [1]. The SLE activity can pdf-space/>be measured by SLEDAI (Systemic Lupus Erythematosus Disease Activity Index), which is a complex tool composed of 24 clinical and laboratory variables, and it requires training and knowledge for its application [2]. Measurement of serum levels of individual complement components is commonly used to diagnose and assess disease activity in SLE. Significantly decreased values of serum $\mathrm{C} 1 \mathrm{q}, \mathrm{C} 3$ and $\mathrm{C} 4$ have been associated with increased SLE disease activity manifested by active nephritis and extrarenal involvement. Besides that, the persistence of $\mathrm{C} 3$ low levels after treatment is an indicator of worse outcome [3,4]. Nevertheless, there is still no reliable laboratory test that can independently quantify this disease activity $[5,6]$. The discovery of new biomarkers capable of monitoring the activity of the disease in a more practical way is essential.

The Mean Platelet Volume (MPV) is a parameter detected by hematological analyzers during routine blood count. The MPV was shown to be a reliable inflammatory marker in several diseases such as ulcerative colitis [7], ankylosing spondylitis, rheumatoid arthritis, rheumatic fever, and even chronic obstructive pulmonary disease [8 - 10], besides being associated with a high risk of stroke [11] and myocardial infarction [12]. This index has been shown to be associated with the inflammatory process, and it is also an important marker of platelet activation and function [5, 6, 13 - 18]. Several studies suggest that MPV may be a good marker of disease activity in SLE, presenting low cost and wide availability $[5,13,15,19]$. Recent studies have found that MPV significantly reduced in patients with active disease $[15,19]$, including negative correlation with SLEDAI [19]. Other study performed in a juvenile SLE (JSLE) population, however, showed significantly higher MPV values in patients compared to healthy controls and in the active disease group when compared to the remission group. There are still doubts regarding the possibility of using MPV as a disease activity biomarker in adult patients with SLE.

Our study aimed to evaluate MPV in adult patients with SLE, and to compare MPV values among SLE patients and healthy individuals. Moreover, we studied the correlation between MPV and disease activity index (SLEDAI) in SLE patients and analyzed a possible correlation among MPV and Erythrocyte Sedimentation Rate (ESR), C-Reactive Protein (CRP), and complement components $\mathrm{C} 3$ and $\mathrm{C} 4$.

\section{MATERIALS AND METHODS}

\subsection{Patients and Study Design}

This is a cross-sectional study with the inclusion of 139 participants. The study population consisted of 81 SLE patients who were followed up at the outpatient clinic of the Rheumatology Service of the Hospital de Clínicas de Porto Alegre (HCPA). Patients were selected consecutively between October 2015 and July 2016. The diagnosis of the disease was established based on the presence of at least four of the 11 criteria of diagnostic classification criteria proposed by the American College of Rheumatology (ACR) in 1982 and revised in 1997 [20]. Patients with an overlap of other diffuse connective tissue diseases (except Sjögren's syndrome and antiphospholipid antibody syndrome) and non-SLE-related hematological diseases such as thalassemia, myeloproliferative disorders, myelofibrosis, BernardSoulier syndrome, and anomaly of May-Hegglin were excluded. Patients with previous or current history of neoplasm, diabetes, uncontrolled systemic arterial hypertension, heart disease, hyperthyroidism, splenectomy, thrombocytopenia, inflammatory bowel disease, psoriasis, acute and chronic infections (hepatitis $\mathrm{B}$, hepatitis $\mathrm{C}$, human immunodeficiency virus infection, tuberculosis and syphilis) were also excluded, as well as patients who underwent blood transfusions three months prior to screening. Healthy individuals were selected among volunteers from the HCPA blood bank, matched by sex and ethnicity. The research project was approved by the ethics committee of the HCPA and all participants were included only after reading, understanding and signing the informed consent form (ICF) in accordance with the Helsinki Declaration.

\subsection{Clinical and Laboratory Variables}

At the time of the consultation, disease activity index was calculated through SLEDAI and disease chronicity index through SLICC damage index [21], respectively. Patients with SLEDAI $>0$ were considered to have active SLE. Data were also collected regarding the treatment used at the time of the consultation and detection of possible exclusion criteria. The patient's chart was reviewed to confirm the diagnostic classification criteria. Blood collection should have been performed within 10 days prior to consultation, when the patient was invited to participate in the study and signed the ICF. 


\subsection{Analytical Methods Used}

Blood counts and platelets were measured on the Sysmex XE 5000 automation equipment. A total of $5 \mathrm{ml}$ of venous blood was taken in an EDTA tube from every participant. All samples were analyzed within 1 hour after collection. The platelets were analyzed by impedance methodology, and the MPV index was calculated by the equipment when the platelet test was performed. MPV was obtained by dividing the platelet count (called platelet hematocrit or platelet volume ratio, weighted for platelet frequency) by the number of platelets.

The C3 and C4 and CRP (C-Reactive Protein) exams were measured by immunoturbidimetry in the SIEMENSADVIA1800 automation equipment. C1q levels measurement is not a part of our outpatient routine exam request and could not be assessed. Anti-dsDNA was performed by immunofluorescence, and anticardiolipin antibodies, performed by the Liaison automation equipment. ESR was performed on the Alere Roller 20 equipment. Urinary sediment was performed on the IQ200-IRIS automation equipment. The lupus anticoagulant was analyzed in the BCS-Siemens automation equipment using reagent LA1 and LA2 (both produced with Russel viper venom at different concentrations) with LA1 screening and LA2 being confirmatory.

\subsection{Statistical Analysis}

Data analysis was performed in SPSS 16.1 software. The comparison of the two groups (patients and controls) was determined by Student's t-test. The results were presented as means and standard deviations. The correlation between the variables was calculated by Pearson's and Spearman's coefficients. ROC curve was performed to determine the value of the MPV Cutoff as a disease activity biomarker. The sensitivity, specificity, positive predictive value and negative predictive value, likelihood ratio and confidence interval and the p-value were also calculated.

To detect a difference between the MVP outcome of SLE patients and the healthy controls, the results obtained by Yavuz S., et al. found a standard deviation of 2.7 and 0.52 respectively. With a ratio of 3 cases to 2 controls, considering a power of $80 \%$ and significance level of $5 \%$, expecting a difference of $1 \mathrm{fL}$ between the groups, a ' $\mathrm{n}$ ' (sample) of 90 patients and 60 controls will be necessary [5].

\section{RESULT}

This study consisted of 81 patients with SLE and 58 healthy controls. The patients were $96.4 \%$ female, $72.3 \%$ Eurodescendants, mean age $42.7 \pm 12.3$ years and mean disease duration of $12.8 \pm 7.8$ years. Fifty-four $(54.4 \%)$ patients had active disease at the time of evaluation. The comparison of clinical and laboratory characteristics of patients with inactive and active disease is described in Tables $\mathbf{1}$ and 2. The group of healthy controls consisted of 89.7\% of women, $89.7 \%$ Euro-descendants with a mean age of $36.4 \pm 11.9$ years. Except for age, total leukocytes count and hemoglobin, SLE and control groups were similar.

Table 1. Demographic, clinical, and laboratorial features of SLE patients.

\begin{tabular}{|c|c|c|c|c|c|}
\hline Patient's Features & $\begin{array}{l}\text { Whole } \\
(n=81)\end{array}$ & $\begin{array}{c}\text { SLEDAI }=0 \\
(n=37)\end{array}$ & $\begin{array}{c}\text { SLEDAI }>0 \\
(n=44)\end{array}$ & $p$ Value* & $\begin{array}{c}\text { Controls } \\
(n=58)\end{array}$ \\
\hline Age (years \pm SD) & $42.7 \pm 12.3$ & $43.6 \pm 12.3$ & $41.8 \pm 12.3$ & 0.519 & $36.4 \pm 11.9^{a}$ \\
\hline Disease duration (years \pm SD) & $12.8 \pm 7.8$ & $13.6 \pm 8,3$ & $12.1 \pm 7.3$ & 0.425 & - \\
\hline Malar rash $(\%)$ & 50.7 & 42.4 & 57.5 & 0.243 & - \\
\hline Discoid rash $(\%)$ & 8.2 & 12.1 & 5.0 & 0.400 & - \\
\hline Photosensitivity (\%) & 68.5 & 63.6 & 72.5 & 0.456 & - \\
\hline Oral ulcers $(\%)$ & 41.1 & 27.3 & 52.5 & 0.034 & - \\
\hline Arthritis (\%) & 72.6 & 69.7 & 75.0 & 0.793 & - \\
\hline Serositis $(\%)$ & 15.3 & 12.1 & 17.9 & 0.533 & - \\
\hline Nephritis (\%) & 47.9 & 42.4 & 52.5 & 0.482 & - \\
\hline Neurologic disorders $(\%)$ & 13.7 & 18.2 & 10.0 & 0.496 & - \\
\hline Hematologic disorders (\%) & 71.2 & 63.6 & 77.5 & 0.207 & - \\
\hline Hemolytic anemia (\%) & 30.1 & 21.2 & 37.5 & 0.200 & - \\
\hline Leukopenia/ Lymphopenia (\%) & 21.5 & 10.8 & 31.0 & 0.053 & - \\
\hline Thrombocytopenia (\%) & 2.5 & - & 4.5 & 0.498 & - \\
\hline Immunologic disorders $(\%)$ & 65.7 & 59.4 & 71.1 & 0.325 & - \\
\hline
\end{tabular}


(Table $\square$ ) contd.....

\begin{tabular}{|c|c|c|c|c|c|}
\hline Patient's Features & $\begin{array}{l}\text { Whole } \\
(n=81)\end{array}$ & $\begin{array}{c}\text { SLEDAI }=0 \\
(n=37)\end{array}$ & $\begin{array}{c}\text { SLEDAI }>0 \\
(n=44)\end{array}$ & $p$ Value* & $\begin{array}{c}\text { Controls } \\
(n=58)\end{array}$ \\
\hline Anti-dsDNA (\%) & 12.8 & 2.8 & 21.4 & 0.017 & - \\
\hline Anti-Sm (\%) & 18.4 & 10.5 & 26.3 & 0.405 & - \\
\hline Anticardiolipin (\%) & 17.1 & 18.8 & 15.8 & 0.761 & - \\
\hline Lupus anticoagulant (\%) & 5.4 & 8.6 & 2.6 & 0.339 & - \\
\hline False positive VDRL $(\%)$ & 1.5 & 0.0 & 2.6 & 1.000 & - \\
\hline ANA $(\%)$ & 98.6 & 100.0 & 97.6 & 1.000 & - \\
\hline Anti-Ro/SSA (\%) & 33.8 & 21.2 & 44.7 & 0.046 & - \\
\hline Anti-La/SSB (\%) & 12.7 & 3.0 & 21.1 & 0.033 & - \\
\hline Anti-RNP (\%) & 26.4 & 18.2 & 33.3 & 0.185 & - \\
\hline Sjögren's syndrome (\%) & 1.5 & 0.0 & 2.9 & 1.000 & - \\
\hline Antiphospholipid syndrome (\%) & 2.9 & 3.0 & 2.7 & 1.000 & - \\
\hline SLEDAI $^{c}$ & $2(0-4)$ & $0(0-0)$ & $4(2-6)$ & $<0.001$ & - \\
\hline SLICC damage index ${ }^{\mathrm{c}}$ & $0(0-1)$ & $0(0-1)$ & $1(0-2)$ & 0.304 & - \\
\hline $\mathrm{MPV}(\mathrm{fL} \pm \mathrm{SD})$ & $10.3 \pm 0.9$ & $10.7 \pm 1.0$ & $10.0 \pm 0.7$ & 0.001 & $10.9 \pm 1.0^{\mathrm{a}}$ \\
\hline $\mathrm{ESR}(\mathrm{mm} / \mathrm{h} \pm \mathrm{SD})$ & $29.3 \pm 17.7$ & $29.0 \pm 18.9$ & $29.5 \pm 16.8$ & 0.896 & - \\
\hline $\mathrm{CRP}(\mathrm{mg} / \mathrm{dL})^{\mathrm{c}}$ & $2.8(1.4-5.3)$ & $2.9(1.3-5.3)$ & $2.6(1.5-5.2)$ & 0.949 & - \\
\hline $\mathrm{C} 3(\mathrm{mg} / \mathrm{dL} \pm \mathrm{SD})$ & $105.3 \pm 27.1$ & $110.1 \pm 21.0$ & $101.3 \pm 30.9$ & 0.135 & - \\
\hline $\mathrm{C} 4(\mathrm{mg} / \mathrm{dL} \pm \mathrm{SD})$ & $19.6 \pm 10.0$ & $20.9 \pm 8.8$ & $18.6 \pm 10.1$ & 0.294 & - \\
\hline Euro-derived ethnicity (\%) & - & $62.2^{\mathrm{a}}$ & 79.5 & - & $89.7^{\mathrm{a}}$ \\
\hline Female (\%) & - & 97.3 & 95.5 & - & 89.7 \\
\hline WBC $(103 / \mathrm{mm} 3)$ & - & $6.55 \pm 2.4^{\mathrm{b}}$ & $5.95 \pm 3.1^{\mathrm{a}, \mathrm{b}}$ & - & $7.47 \pm 1.9$ \\
\hline Hemoglobin $(\mathrm{g} / \mathrm{dl})$ & - & $12.7 \pm 1.0^{\mathrm{a}}$ & $12.1 \pm 1.4^{\mathrm{a}}$ & - & $14.1 \pm 0.9^{\mathrm{a}}$ \\
\hline Platelets (103/mm3) & - & $244.0 \pm 49.5$ & $270.4 \pm 105.7$ & - & $274.6 \pm 57.8$ \\
\hline
\end{tabular}

Abbreviations: ANA: Antinuclear Antibody; CRP: C-Reactive Protein; ESR: Erythrocyte Sedimentation Rate; SD: Standard Deviation; SLEDAI: Systemic Lupus Erythematous Disease Activity Index; SLICC: Systemic Lupus International Collaborating Clinics; MPV: Mean Platelet Volume; VDRL: Venereal Disease Research Laboratory Test; WBC: White Blood Cells. * Chi square test for qualitative variables and ANOVA for quantitative variables, and Tukey test. ** Chi square test for qualitative variables and Mann-Whitney for asymmetric quantitative variables or Student's $t$ test for symmetric quantitative variables. ${ }^{\mathrm{a}} p$-value $<0.05$ between patients and controls. ${ }^{\mathrm{b}} p$-value $<0.05$ between active and inactive patients. ${ }^{\mathrm{c}}$ Median (interquartile range).

Table 2. Description of treatment in patients with inactive and active lupus.

\begin{tabular}{|c|c|c|c|}
\hline Medications & $\begin{array}{c}\text { SLEDAI }=0 \\
(n=37)\end{array}$ & $\begin{array}{c}\text { SLEDAI }>0 \\
(n=44)\end{array}$ & $p$ Value* \\
\hline Corticosteroids $(\%)$ & 32.4 & 47.8 & 0.183 \\
\hline Immunosuppressive dose $(\%)$ & 37.8 & 23.9 & 0.229 \\
\hline Antimalarial (\%) & 86.5 & 73.9 & 0.182 \\
\hline Azathioprine (\%) & 40.5 & 45.7 & 0.663 \\
\hline Cyclophosphamide (\%) & 5.4 & 13.0 & 0.289 \\
\hline Micophenolate (\%) & 11.1 & 11.4 & 1.000 \\
\hline Methotrexate $(\%)$ & 8.1 & 4.3 & 0.652 \\
\hline Anti-hypertensive drugs (\%) & 45.9 & 63.0 & 0.128 \\
\hline Statins $(\%)$ & 18.8 & 24.3 & 0.771 \\
\hline
\end{tabular}

ANA: Antinuclear Antibody; CRP: C-Reactive Protein; ESR: Erythrocyte Sedimentation Rate; SD: Standard Deviation; SLEDAI: Systemic Lupus Erythematous Disease Activity Index; SLICC: Systemic Lupus International Collaborating Clinics; MPV: Mean Platelet Volume; VDRL: Venereal Disease Research Laboratory Test. *Chi square test for qualitative

The mean MPV of SLE patients was $10.3 \pm 0.9 \mathrm{fL}$, while that of the control group being $10.9 \pm 1.0 \mathrm{fL}(p<0,001)$. When we analyzed patients with SLE, the group with active disease presented mean MPV of $10.0 \pm 0.7 \mathrm{fL}$ and the group with disease in remission $10.7 \pm 1.0 \mathrm{fL}(p<0.001)$.

Table 3 describes the treatment received by the patients. There was not a significant difference of how the patients were treated when comparing the SLE patients with active or inactive disease. 
Table 3. Laboratory parameters for identification of SLEDAI $>0$.

\begin{tabular}{|c|c|c|c|c|c|}
\hline- & MPV & CRP & ESR & C3 \\
\hline Sensitivity & $61 \%$ & $41 \%$ & $41 \%$ & $23 \%$ \\
\hline Specificity & $24 \%$ & $63 \%$ & $78 \%$ & $81 \%$ & $54 \%$ \\
\hline PPV & $49 \%$ & $58 \%$ & $69 \%$ & $59 \%$ & $47 \%$ \\
\hline PNV & $35 \%$ & $46 \%$ & $53 \%$ & $40 \%$ \\
\hline Cutoff level & $9.85 \mathrm{fL}$ & $3.65 \mathrm{mg} / \mathrm{dL}$ & $35.5 \mathrm{~mm} / \mathrm{Hg}$ & $122.5 \mathrm{mg} / \mathrm{dL}$ & $15.5 \mathrm{mg} / \mathrm{dL}$ \\
\hline
\end{tabular}

PPV: Positive Predictive Value; PNV: Negative Predictive Value.

The MPV showed a negative correlation with the SLEDAI, which was, although weak, statistically significant $(r=-0.29, p=0.009)$ Fig. (1). MPV results did not show statistically significant correlation with CPR, ESR and C3 and C4 complements $(p=0.562, p=0.796, p=0.427, p=0.977$, respectively). SLEDAI also did not present a statistically significant correlation with CRP, ESR, $\mathrm{C} 3$ and $\mathrm{C} 4(p=0.856, p=0.640, p=0.300, p=0.415$, respectively). Fig. (2) shows the sensitivity versus the specificity for different cutoff levels of MPV, ESR, CRP, C3 and C4.

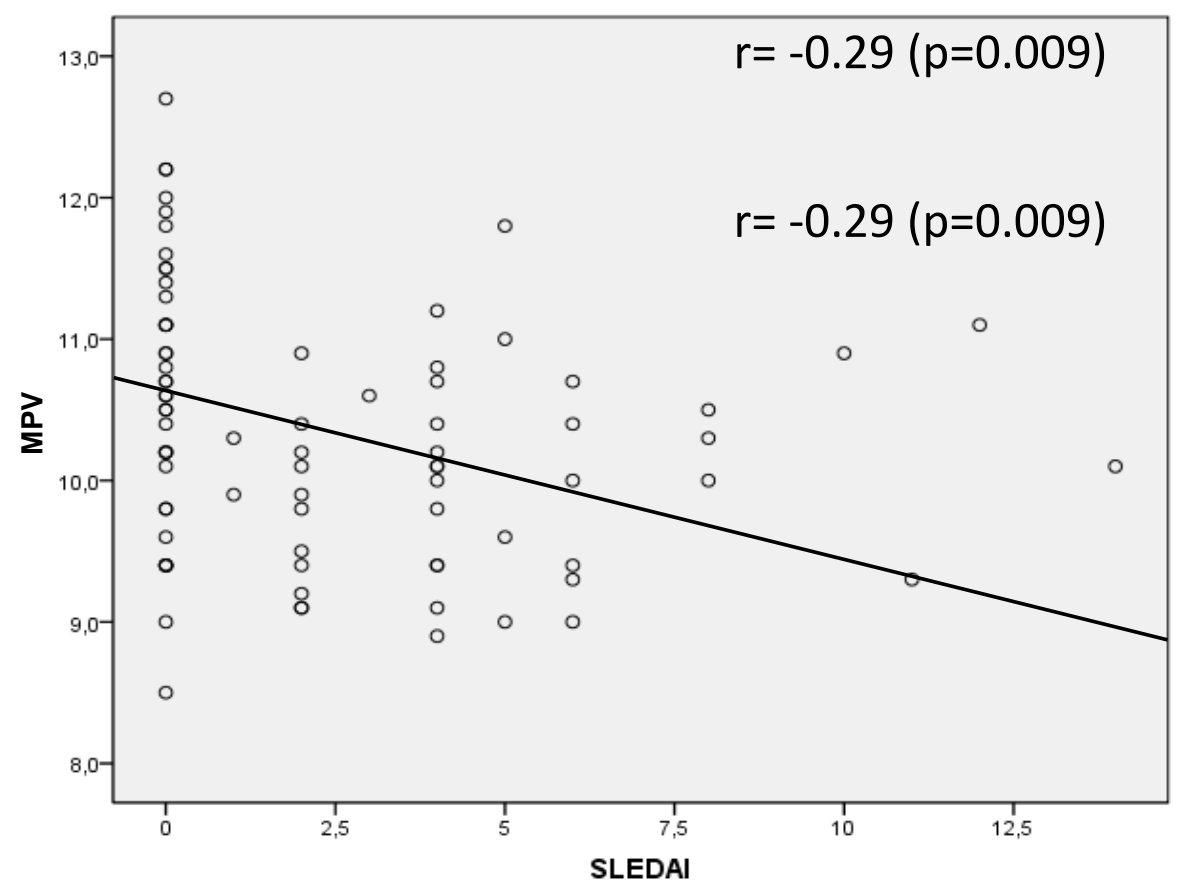

Fig. (1). The correlation between MPV and SLEDAI.

\section{DISCUSSION}

Our study found significantly lower values of MPV in patients with active SLE when compared to patients in remission. In SLE, lower platelet size has been linked to platelet activation. Platelet system activation is a key event in the pathogenesis of SLE. Immune Complexes (ICs) from SLE sera are potent activators of platelets through their binding to Fc $\gamma$ RIIA (CD32) on platelets' surface. SLE ICs could also act through Toll-Like Receptor-4 (TLR-4) or TLR-7, as TLR-4 and TLR-7 agonists promote platelet activation [22, 23]. Antiphospholipid antibodies (ApL) can mediate platelet activation directly through interaction with a platelet's plasma membrane, by binding diverse platelet receptors and/or by promoting complement deposition on platelets [24]. Lastly, infectious agents such as a virus can activate platelets in SLE. Upon viral infection, platelets are activated through TLR7, which induces a change in their phenotype, leading to the formation of platelet-neutrophil aggregates. These aggregates ultimately lead to platelet internalization and thrombocytopenia without the promotion of thrombosis [25]. Upon activation, platelets promote type I interferon production, NETosis, dendritic cell activation, and T and B lymphocyte activation, all essential events contributing to the development of SLE [26].

Other studies have found results similar to ours $[13,15,19]$. In rheumatoid arthritis, there is a study that also demonstrated diminished results of MPV in the active disease. In this study, after the patients' treatment, the values of 
the MPV increased [27]. Similar results were obtained in a study with adult patients with active ankylosing spondylitis, where MPV was analyzed before and after treatment, and the MPV values showed a significant increase after the treatment [16].

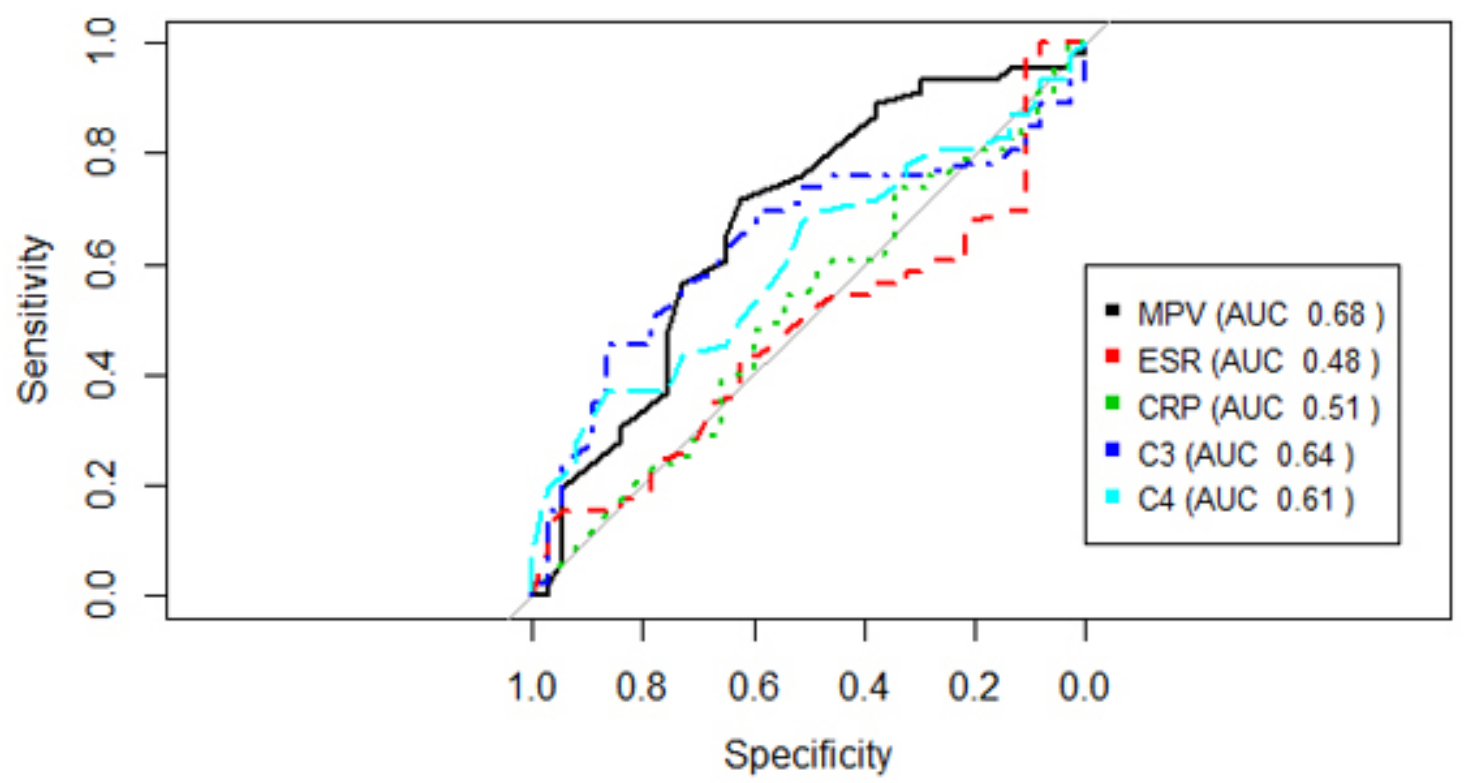

Fig. (2). Sensitivity versus the specificity for different cutoff levels of MPV, ESR, CRP, C3 and C4.

MPV has been considered a possible marker of platelet activation and inflammatory process [13]. The pathophysiology of SLE involves the presence of inflammatory cytokines and deregulation of the complement system, which interferes with the activation of platelets [15]. A probable mechanism that may explain the relationship between reduced MPV and disease activity is the consumption of large platelets at sites of inflammation $[6,15]$.

Although our MPV results did not show statistically significant correlation with the parameters of CRP, ESR and $\mathrm{C} 3$ and $\mathrm{C} 4$ complement components, we found a negative correlation between MPV and SLEDAI, similar to that found by Khan A., et al. [19]. Although the correlation was weak, it confirms that the diminished results of MPV in patients with active SLE are linked to the disease activity. It is well known that CRP and ESR are not good biomarkers of disease activity in SLE. However, as C3 and C4 complement components are 1 part of the 24 items evaluated in SLEDAI, it would be expected to have some correlation with the variation in disease activity, a fact that was not observed in the present study. A plausible explanation would be a bias selection of patients with low complement intake as one of the scoring items in SLEDAI.

Yavuz S., et al., in a study with individuals with juvenile SLE, found higher MPV values in patients with active disease compared to the remission group [5]. In the same study, there was also a positive correlation with SLEDAI, ESR, CRP and protein and creatinine ratio in a urinary sample [5]. Perhaps this discrepancy occurs due to the inherent characteristics of the treatment or study population. SLE is a chronic autoimmune disease that intersperses periods of activity and remission, and the JSLE presents a worse prognosis than SLE in adults, requiring a more aggressive immunosuppressive therapy. Another aspect that should be considered is that the study with JSLE was conducted on a small sample of patients, having evaluated only 20 children. Other previous studies have shown a probable relationship between high values of MPV and active inflammatory disease [6, 28]. Recently another study with 128 patients found higher MPV values in active LES and a moderate correlation between MPV and SLEDAI score [29]. Several factors may explain these differences: the pre-analytical handling of the samples, which is a key issue; the presence of antiphospholipid antibodies, and several other known or unknown cofactors, making difficult the clinical assumptions based on MPV [23, 30].

Our study also showed decreased MPV results in active patients when compared to healthy controls, this result was consistent with the study performed in patients with inflammatory bowel disease; however, in our study, the results of 
the patients in remission were similar to the results of the MPV in the controls. And in the study performed with inflammatory bowel disease, the results of the MPV in patients in remission were also decreased when compared to control group [31]. In a Meta-analysis evaluating the relationship between hematological indices and autoimmune rheumatic diseases, Hao and coworkers did not find significative difference related to MVP comparing SLE patients with healthy control group. However, in relation to this analysis, only two studies were included and there was important heterogeneity between them [32].

The MPV is an easily measurable parameter, and has shown high sensitivity (86\%) in a previous study so it may be considered a potential candidate for activity biomarker in SLE [15]. Although the MPV presented pre-analytical interferences related to the time of collection, sample storage and the anticoagulant used [28], these variables were controlled in our study. In addition, we evaluated the treatment used in the patients of the active and inactive groups, and there was no statistically significant difference between them. Our results were similar to the recently performed study with patients with active and inactive SLE at similar sampling [15].

Total leukocyte count and hemoglobin were reduced in active SLE Table 1. No difference was found between active and inactive SLE regarding the medications used by the patients Table 2 . These results are consistent with those from the literature.

Our study has several limitations. It cannot establish a causal relationship because of its transversal design. There was no age pairing between the SLE groups and the control group. The active disease group had an average SLEDAI of 4 (disease with mild activity), while the other studies included patients with more active disease in this group (SLEDAI mean $>16$ ) $[5,19]$. Even though SLEDAI showed little difference between the active SLE and remission groups, there was no difference in treatment between these groups. Patients with antiphospholipid antibody syndrome were not excluded from this study. The increase of MPV in patients with this syndrome is described in comparison to control patients [33]. However, only 1 patient in the SLE group in remission and 1 patient in the active SLE group presented APS. Previous studies have shown increased MPV in patients with Chronic Obstructive Pulmonary Disease (COPD) [9, 34, 35]. In our study 5 patients with COPD were included, 4 in the active SLE group and 1 in the SLE remission group. This bias was conservative, because despite presenting a greater number of patients with COPD, MPV was still significantly lower in the active SLE group. There was a difference between the use of aspirin between the groups (10 patients with active SLE and 7 patients with SLE in remission), but previous studies did not find a significant effect on the MPV with the use of low dose aspirin (up to $100 \mathrm{mg}$ daily) [36, 37]. Another relevant point is the impossibility of defining how the MPV could be used against other biomarkers of systemic inflammation (CRP and ESR), since the ROC curves were similar.

Although the number of patients included in the study was slightly lower than the sample size, there was a statistically significant difference of the MPV in the active SLE group in relation to inactive SLE and controls.

The mean MPV difference between the groups, however, was small (less than $1 \mathrm{fL}$ ). The least variation in the MPV values observed in our study ( $\mathrm{SD} \pm 0.7, \pm 1.0$ and \pm 1.0 in the active SLE, SLE in remission and controls, respectively) compared to those found by Yavuz et al ( $\mathrm{SD} \pm 2.7 \pm 0.86$ and \pm 0.52 in the active LES, SLE in remission and controls, respectively) may explain this statistical significance, even with a lower MPV difference. However, the clinical relevance of this small difference is quite questionable.

At last, the platelet-derived microparticles (PMPs) were not evaluated in our work. It was recently shown that PMPs are generated after platelet activation and were shown to play a role in hemostasis, thrombosis, cancer, inflammation and autoimmunity. Moreover, circulating PMPs were increased in lupus nephritis and correlated with high blood pressure and proteinuria, two prognostic factors in lupus suggesting a direct role of PMPs in the pathogenesis of lupus nephritis $[26,38]$.

We conclude that MPV is reduced in patients with active SLE and presents an inverse correlation with SLEDAI. Despite the difference between MVP values and between active and inactive SLE patients, the results may not be clinically relevant. Prospective longitudinal studies are needed to better characterize the fluctuation of MPV in different stages of disease activity to more clearly define the role of MPV in SLE.

\section{ETHICS APPROVAL AND CONSENT TO PARTICIPATE}

The research project was approved by the ethics committee of the HCPA. 


\section{HUMAN AND ANIMAL RIGHTS}

No Animals were used in this research. All human research procedures followed were in accordance with the ethical standards of the committee responsible for human experimentation (institutional and national), and with the Helsinki Declaration of 1975, as revised in 2013.

\section{CONSENT FOR PUBLICATION}

All participants were included only after reading, understanding and signing the informed consent form (ICF).

\section{CONFLICT OF INTEREST}

The authors declare no conflict of interest, financial or otherwise.

\section{ACKNOWLEDGEMENTS}

This study was supported by grants from (Research Incentive and Events Fund) of the Hospital de Clínicas de Porto Alegre, CAPES (Coordination for the Improvement of Higher Level Personnel), Research Support Fund of the Rheumatology Society of Rio Grande do Sul.and CNPq (National Council for Scientific and Technological Development.

\section{REFERENCES}

[1] Manson JJ, Isenberg DA. The pathogenesis of systemic lupus erythematosus. Neth J Med 2003; 61(11): 343-6. [PMID: 14768716]

[2] Mosca M, Bombardieri S. Assessing remission in systemic lupus erythematosus. Clin Exp Rheumatol 2006; 24(6)(Suppl. 43): S-99-S-104. [PMID: 17083771]

[3] Moroni G, Trendelenburg M, Del Papa N, et al. Anti-C1q antibodies may help in diagnosing a renal flare in lupus nephritis. Am J Kidney Dis 2001; 37(3): 490-8.

[http://dx.doi.org/10.1053/ajkd.2001.22071] [PMID: 11228172]

[4] Swaak AJ, Groenwold J, Bronsveld W. Predictive value of complement profiles and anti-dsDNA in systemic lupus erythematosus. Ann Rheum Dis 1986; 45(5): 359-66. [http://dx.doi.org/10.1136/ard.45.5.359] [PMID: 3487292]

[5] Yavuz S, Ece A. Mean platelet volume as an indicator of disease activity in juvenile SLE. Clin Rheumatol 2014; 33(5): 637-41. [http://dx.doi.org/10.1007/s10067-014-2540-3] [PMID: 24567240]

[6] Gasparyan AY, Ayvazyan L, Mikhailidis DP, Kitas GD. Mean platelet volume: A link between thrombosis and inflammation? Curr Pharm Des 2011; 17(1): 47-58 [http://dx.doi.org/10.2174/138161211795049804] [PMID: 21247392]

[7] Yüksel O, Helvaci K, Başar O, et al. An overlooked indicator of disease activity in ulcerative colitis: Mean platelet volume. Platelets 2009; 20(4): 277-81.

[http://dx.doi.org/10.1080/09537100902856781] [PMID: 19459134]

[8] Şahin A, Yetişgin A, Şahin M, Durmaz Y, Cengiz AK. Can mean platelet volume be a surrogate marker of inflammation in rheumatic diseases? West Indian Med J 2015; 65(1): 165-9. [http://dx.doi.org/10.7727/wimj.2014.202] [PMID: 26645595]

[9] Zhang M, Li Y, Zhang J, et al. Mean platelet volume is elevated in exacerbated and convalescent COPD patients. Clin Chim Acta 2015; 451(Pt B): 227-31. [http://dx.doi.org/10.1016/j.cca.2015.10.001] [PMID: 26436484]

[10] Ulasli SS, Ozyurek BA, Yilmaz EB, Ulubay G. Mean platelet volume as an inflammatory marker in acute exacerbation of chronic obstructive pulmonary disease. Pol Arch Med Wewn 2012; 122(6): 284-90. [http://dx.doi.org/10.20452/pamw.1284] [PMID: 22576316]

[11] Bath P, Algert C, Chapman N, Neal B. Association of mean platelet volume with risk of stroke among 3134 individuals with history of cerebrovascular disease. Stroke 2004; 35(3): 622-6. [http://dx.doi.org/10.1161/01.STR.0000116105.26237.EC] [PMID: 14976328]

[12] Endler G, Klimesch A, Sunder-Plassmann H, et al. Mean platelet volume is an independent risk factor for myocardial infarction but not for coronary artery disease. Br J Haematol 2002; 117(2): 399-404. [http://dx.doi.org/10.1046/j.1365-2141.2002.03441.x] [PMID: 11972524]

[13] Safak S, Uslu AU, Serdal K, Turker T, Soner S, Lutfi A. Association between mean platelet volume levels and inflammation in SLE patients presented with arthritis. Afr Health Sci 2014; 14(4): 919-24. [http://dx.doi.org/10.4314/ahs.v14i4.21] [PMID: 25834502] 
[14] Işık M, Şahin H, Hüseyin E. New platelet indices as inflammatory parameters for patients with rheumatoid arthritis. Eur J Rheumatol 2014; 1(4): 144-6.

[http://dx.doi.org/10.5152/eurjrheumatol.2014.140023] [PMID: 27708900]

[15] Delgado-García G, Galarza-Delgado DÁ, Colunga-Pedraza I, et al. Mean platelet volume is decreased in adults with active lupus disease. Rev Bras Reumatol 2016. S0482-5004(16)00029-2 [http://dx.doi.org/10.1016/j.rbr.2015.12.003] [PMID: 26968762]

[16] Kisacik B, Tufan A, Kalyoncu U, et al. Mean Platelet Volume (MPV) as an inflammatory marker in ankylosing spondylitis and rheumatoid arthritis. Joint Bone Spine 2008; 75(3): 291-4.

[http://dx.doi.org/10.1016/j.jbspin.2007.06.016] [PMID: 18403245]

[17] Farias MG, Dal Bó S. Clinical and laboratory significance of mean platelet volume. J Bras Patol Med Lab $2010 ; 46$ [http://dx.doi.org/10.1590/S1676-24442010000400003]

[18] Yazici S, Yazici M, Erer B, et al. The platelet indices in patients with rheumatoid arthritis: Mean platelet volume reflects disease activity. Platelets 2010; 21(2): 122-5.

[http://dx.doi.org/10.3109/09537100903474373] [PMID: 20050760]

[19] Khan A, Haider I, Ayub M, Khan S. Monitoring disease activity and severity in lupus. F1000 Res 2017; 6: 126. [http://dx.doi.org/10.12688/f1000research.10763.3]

[20] Tan EM, Cohen AS, Fries JF, et al. The 1982 revised criteria for the classification of systemic lupus erythematosus. Arthritis Rheum 1982; 25(11): 1271-7. [http://dx.doi.org/10.1002/art.1780251101] [PMID: 7138600]

[21] Petri M, Orbai A-M, Alarcón GS, et al. Derivation and validation of the systemic lupus international collaborating clinics classification criteria for systemic lupus erythematosus. Arthritis Rheum 2012; 64(8): 2677-86. [http://dx.doi.org/10.1002/art.34473] [PMID: 22553077]

[22] Sokolove J, Zhao X, Chandra PE, Robinson WH. Immune complexes containing citrullinated fibrinogen costimulate macrophages via Tolllike receptor 4 and Fc $\gamma$ receptor. Arthritis Rheum 2011; 63(1): 53-62.

[http://dx.doi.org/10.1002/art.30081] [PMID: 20954191]

[23] Lood C, Tydén H, Gullstrand B, et al. Decreased platelet size is associated with platelet activation and anti-phospholipid syndrome in systemic lupus erythematosus. Rheumatology (Oxford) 2017; 56(3): 408-16. [http://dx.doi.org/10.1093/rheumatology/kew437] [PMID: 28031442]

[24] Lood C, Tydén H, Gullstrand B, et al. Platelet activation and anti-phospholipid antibodies collaborate in the activation of the complement system on platelets in systemic lupus erythematosus. PLoS One 2014; 9(6): e99386.

[http://dx.doi.org/10.1371/journal.pone.0099386] [PMID: 24922069]

[25] Koupenova M, Vitseva O, MacKay CR, et al. Platelet-TLR7 mediates host survival and platelet count during viral infection in the absence of platelet-dependent thrombosis. Blood 2014; 124(5): 791-802.

[http://dx.doi.org/10.1182/blood-2013-11-536003] [PMID: 24755410]

[26] Scherlinger M, Sisirak V, Richez C, Lazaro E, Duffau P, Blanco P. New insights on platelets and platelet-derived microparticles in systemic lupus erythematosus. Curr Rheumatol Rep 2017; 19(8): 48. [http://dx.doi.org/10.1007/s11926-017-0678-0] [PMID: 28718063]

[27] Kim D-A, Kim T-Y. Controversies over the interpretation of changes of mean platelet volume in rheumatoid arthritis. Platelets 2011; 22(1): 79-80.

[http://dx.doi.org/10.3109/09537101003663758] [PMID: 21194397]

[28] Leader A, Pereg D, Lishner M. Are platelet volume indices of clinical use? A multidisciplinary review. Ann Med 2012; 44(8): 805-16. [http://dx.doi.org/10.3109/07853890.2011.653391] [PMID: 22413913]

[29] Bai M, Xing L, Feng J, Cui C, Huang L, Liang G. Mean platelet volume could reflect disease activity of adult patients with systemic lupus erythematosus. Clin Lab 2016; 62(7): 1317-22. [PMID: 28164649]

[30] Şahin A, Yetişgin A, Şahin M, Durmaz Y, Cengiz AK. Can mean platelet volume be a surrogate marker of inflammation in rheumatic diseases? West Indian Med J 2015; 65(1): 165-9. [http://dx.doi.org/10.7727/wimj.2014.202] [PMID: 26645595]

[31] Öztürk ZA, Dag MS, Kuyumcu ME, et al. Could platelet indices be new biomarkers for inflammatory bowel diseases? Eur Rev Med Pharmacol Sci 2013; 17(3): 334-41. [PMID: 23426536]

[32] Hao X, Li D, Wu D, Zhang N. The relationship between hematological indices and autoimmune rheumatic diseases (ARDs), A meta-analysis. Sci Rep 2017; 7(1): 10833 .

[http://dx.doi.org/10.1038/s41598-017-11398-4] [PMID: 28883472]

[33] Rupa-Matysek J, Gil L, Wojtasińska E, Ciepłuch K, Lewandowska M, Komarnicki M. The relationship between mean platelet volume and thrombosis recurrence in patients diagnosed with antiphospholipid syndrome. Rheumatol Int 2014; 34(11): 1599-605. [http://dx.doi.org/10.1007/s00296-014-2996-0] [PMID: 24671503] 
[34] Onder I, Topcu S, Dökmetas HS, Türkay C, Seyfikli Z. Platelet aggregation size and volume in chronic obstructive pulmonary disease. Mater Med Pol 1997; 29(1-4): 11-3.

[PMID: 10214464]

[35] Bansal R, Gupta HL, Goel A, Yadav M. Association of increased platelet volume in patients of chronic obstructive pulmonary disease : Clinical implications. Jiacm 2002; 3: 169-72.

[36] Szabo FK, Hoffman GE. NIH Public Access 2012; 37: 62-70.

[37] Colkesen Y, Coskun I, Muderrisoglu H. The effect of aspirin on mean platelet volume in patients with paroxysmal atrial fibrillation. Platelets 2013; 24(4): 263-6. [http://dx.doi.org/10.3109/09537104.2012.682106] [PMID: 22647033]

[38] Lu G-Y, Xu R-J, Zhang S-H, et al. Alteration of circulatory platelet microparticles and endothelial microparticles in patients with chronic kidney disease. Int J Clin Exp Med 2015; 8(9): 16704-8.

[PMID: 26629207]

(C) 2018 Hartmann et al.

This is an open access article distributed under the terms of the Creative Commons Attribution 4.0 International Public License (CC-BY 4.0), a copy of which is available at: (https://creativecommons.org/licenses/by/4.0/legalcode). This license permits unrestricted use, distribution, and reproduction in any medium, provided the original author and source are credited. 